\title{
A PRESERVAÇÃO DO DIREITO À VIDA E UMA DISCUSSÃO SOBRE O PODER DE LEGISLAR: A EQUIPARAÇÃO DA TRANSFOBIA E DA HOMOFOBIA AO RACISMO
}

\author{
Ester Oliveira Ferreira Aragão ${ }^{1}$ \\ Adriano César Oliveira Nóbrega ${ }^{2}$
}

\section{RESUMO}

O trabalho objetivou estudar a defesa dos direitos da comunidade LGBTQIA+, correlacionando os avanços traçados pelo Legislativo, Judiciário, ONGs e sociedade. Foi utilizada pesquisa bibliográfica e jurisprudencial sobre a equiparação da homotransfobia ao racismo com a finalidade de verificar se a decisão do STF possui legitimidade. Restou verificado a vida enquanto um direito fundamental para, empós, analisar o ativismo judicial face ao princípio da reserva legal penal e competências legislativas na ótica de Dworkin e Waldron. Concluiu-se que há necessidade de criminalização da homotransfobia, mas que a postura do STF diante do caso em análise possuiu dois vieses contraditórios.

Palavras-chave: Direito Fundamental. Direito à Vida. Controle de Constitucionalidade. Crime de Racismo. Homotransfobia.

\section{PRESERVATION OF THE RIGHT TO LIFE AND A DISCUSSION ON THE POWER OF LEGISLATION: EQUIPARANTING TRANSPHOBIA AND HOMOPHOBIA TO RACISM}

\begin{abstract}
The work aimed to study the defense of rights of the LGBTQIA+ community, correlating the progress made by the legislature, the judiciary and society. Bibliographic and jurisprudential research was used on the equation of homotransphobia to racism to verify if the STF decision has legitimacy. Life remained as a fundamental right and analyze judicial activism in the light of the principle of legal reserve and legislative powers from the perspective of Dworkin and Waldron. It was concluded that there is a need for criminalization of homotransphobia, but that the attitude of the STF before the case under analysis had contradictions.
\end{abstract}

Keywords: Fundamental Right; Right to Life; Constitutional Control; Racism; Homotransphobia.

\section{INTRODUÇÃO}

\footnotetext{
${ }^{1}$ Mestranda em Direito pelo Centro Universitário Christus (UNICHRISTUS). Pós-graduada em Direito Penal pela Universidade de Fortaleza (UNIFOR). Graduada pela Universidade de Fortaleza (UNIFOR). Residente na Rua Gustavo Sampaio, 382, Parque Araxá, Fortaleza, CE, CEP: 60.455-001. Email: ester.f.aragao@ gmail.com 2 Mestre em Direito pela Unichristus (Fortaleza/CE). Pós-graduado em Direito Processual Civil pela Universidade de Fortaleza (UNIFOR). Professor do Centro Universitário Fametro (UNIFAMETRO) e do Centro Universitário Estácio do Ceará (ESTÁCIO). Advogado. Residente na Rua dos Manguesais, 60, ap. 1202, Superiore, Dionísio Torres, Fortaleza, CE, CEP: 61.135-460. Email: adrianonobrega@ outlook.com
} 
Historicamente, a homoafetividade recebeu reprovação no mundo ocidental por razões religiosas, ao não se aceitar o relacionamento entre pessoas do mesmo sexo. Para a Igreja Católica, mulheres que se relacionavam entre si cometiam mera lascívia; já com o relacionamento entre homens, a religião condenava pela perda de sêmen, a qual deveria ser utilizada apenas para a procriação (DIAS apud LEHFELD; MENDONÇA, 2015).

O preconceito, no entanto, foi sendo disseminado, desprendendo-se mesmo de motivos religiosos, colocando pessoas à margem da sociedade, facilitando a usurpação de direitos e alcançando vários níveis de discriminação, entre eles ações criminosas como assassinatos e agressões (físicas e psicológicas), sejam elas no âmbito familiar, profissional ou pessoal.

É certo que avanços em sentido contrário, em prol da proteção de direitos, foram realizados. Como exemplo, é possível citar no Brasil lutas de grupos organizados da sociedade civil no Legislativo e no Judiciário para requerer a garantia de direitos de expressar e assegurar sua afetividade e identidade.

Pode-se citar como avanços do Legislativo o Projeto de Lei no 7.292 de 2017 intitulado "Lei Dandara" (BRASIL, 2019/b, Online), estabelecendo como qualificadora a prática de homicídio contra pessoas identificadas como LGBT. Tem-se uma raiz sociológica para essa proteção diferenciada, por ser o Brasil o país que mais mata travestis e transexuais (ALVES, 2019, Online).

No âmbito judicial, recentemente no dia 23 de maio de 2019, a maioria dos ministros do STF decidiu que homofobia é crime. Seis dos onze ministros votaram por criminalizá-la, equiparando as penas por ofensas a homossexuais e a transexuais às previstas na lei contra o racismo (ROSSI, 2019, Online).

Duas ações haviam sido movidas perante o Supremo: uma pelo antigo Partido Popular Socialista (PPS), hoje denominado de Cidadania (em 2012 e 2013), e outra pela Associação Brasileira de Lésbicas, Gays, Bissexuais, Travestis, Transgêneros e Intersexos (ABGLT) (ROSSI, 2019, Online).

Estabeleceu-se, assim, com tais medidas, o debate sobre o poder de legislar na esfera penal, especialmente em face da omissão legislativa em proteger direitos de minorias. $\mathrm{O}$ Supremo Tribunal Federal assegurou a si mesmo a capacidade de colmatar positivamente a inércia legislativa como meio de atuação para proteger minorias sociais (ROSSI, 2019, Online). Restou estipulado prazo para que o Legislativo crie lei específica para os crimes de 
homofobia, quando até então julgou-se aplicável a legislação análoga provisoriamente. Não é uma completa novidade, pois em mandados de injunções e mesmo em outras ADIs por omissão anteriores já se havia abandonado a ideia de atuação do tribunal apenas para declarar a mora legislativa, sendo-lhe autorizado a diretamente prover o disciplinamento jurídico faltante. No entanto, foi a primeira vez que se fez isso em âmbito penal, em que o princípio da legalidade estrita é pedra angular em delinear seu perfil.

Em paralelo, foi aprovado na Comissão de Constituição e Justiça (CCJ) do Congresso Nacional o projeto de lei 672/2019, que prevê incluir na Lei de Racismo a discriminação por orientação sexual ou identidade de gênero (BRASIL, 2019/a, Online), mas até o efetivo término do processo legislativo, haverá a aplicação analógica determinada pelo Supremo Tribunal Federal. Comportamento que declaradamente não era objeto de prévia cominação legal como crime, o Judiciário passou a qualificar como tal.

Para isso, faz-se necessário a discussão sobre o poder de legislar já que o princípio da reserva legal ou legalidade em sentido estrito afirma que em matéria penal somente o legislador pode criar tipos penais (garantia da lex populi). A lei penal deve obrigatoriamente emanar do Poder Legislativo, pois este é competente para expressar a vontade geral (GOMES, 2017). A lei penal tem que ser clara e objetiva (princípio da taxatividade). Somente é aceita a lei que delimita a conduta lesiva, que põe em perigo um bem jurídico de relevância tutelado pelo Estado e que prescreve uma consequência penal.

Ademais, será exposta a importância do debate sobre o poder de legislar em matéria penal no país, e a necessidade de proteção aos direitos fundamentais das minorias sociais, como resguardar o direito e tutela da comunidade LGBTQIA+, a fim de perquirir se a solução tomada será a mais condizente com a ordem constitucional.

\section{DIREITO FUNDAMENTAL: DIREITO À VIDA}

O direito à vida é fundamental e direito básico concebido a todos, sem distinção de origem, raça, sexo, cor, idade. Esse direito serve de base para a criação dos demais diversos direitos fundamentais. Conforme afirma Alexandre de Moraes, "o direito à vida é o mais fundamental de todos os direitos, já que se constitui em pré-requisito à existência e exercício de todos os demais" (MORAES, 2005, p. 30). 
Gregorio Robles, em sua obra Los derechos fundamentales y la ética em la sociedad actual, inicialmente trata os direitos humanos não como direitos propriamente ditos, mas sim como pautas morais que devem ser reconhecidas e colocadas em prática para, somente com a sua aplicação empírica, serem considerados direitos humanos (1992, p. 19). A análise de Robles parte da ideia de que, em um sistema jurídico positivo, ou até mesmo pós-positivista ${ }^{3}$, o direito humano só existiria quando positivado, enquanto para o direito natural a concepção empregada de direitos humanos dispensaria a previsão positiva.

É necessário reconhecer que o significado de "direitos humanos" transpassa a virada linguística e como as expressões mudam de acordo com o tempo e local analisado, entendendo-se que a linguagem é uma herança cultural a qual não se pode renunciar. Desse modo, o Robles (1992, p. 19-20) não se propõe a deixar de utilizar o termo "direitos humanos", mas que apenas deve-se passar a atribuir ao termo o seu verdadeiro significado, posto que, os "direitos humanos" não são, em verdade, autênticos direitos - protegidos mediante ação processual ante um juiz - senão critérios morais de especial relevância para a convivência humana. No momento em que um "direito humano" reconhecido pelo ordenamento jurídico, há uma alteração que merece análise, pois

\begin{abstract}
Assim, uma vez que os "direitos humanos" são positivados, adquirindo, assim, categoria de verdadeiros direitos protegidos processualmente, passam a ser "direitos fundamentais" em um determinado ordenamento jurídico. Ocorre que, isso somente acontece quando o ordenamento jurídico dota tais direitos de um status especial, tornando-os mais importantes que os demais direitos, pois, se assim não o fosse, não haveria modo de distinguir os direitos fundamentais daqueles que não o são. (ROBLES, 1992, p. 20)
\end{abstract}

A problemática em questão refere-se a quais são os direitos fundamentais que devem ser tutelados no nosso ordenamento jurídico, e qual a melhor maneira para isso poder se dar. Robles cita uma famosa frase de Bobbio "de que el problema de os derechos humanos no es fundamentarlos, sino realizarlos o protegerlos", isto é, que o problema dos direitos humanos não é baseá-los, mas executá-los ou protegê-los (tradução própria).

Para Luigi Ferrajoli (2011), pode-se responder o que são direitos fundamentais pelo prisma de quatro respostas distintas: 1) através do ponto de vista da justiça, ele indaga sobre quais direitos fundamentais devem ser tutelados, concluindo que é necessário fazer uma

\footnotetext{
${ }^{3}$ Utiliza-se esse termo apenas para evitar o debate sobre a adequada acepção das teorias que surgiram após o positivismo, como, por exemplo, as teorias de direito de Alexy e Hart. É possível reconhecer que o termo "póspositivismo" concebe uma superação do positivismo, o que, ao analisar as correntes filosóficas da teoria do Direito, isso não ocorreu.
} 
reflexão sobre os critérios meta-éticos ou meta-políticos, isto é, a convivência pacífica, a igualdade e a dignidade das pessoas as suas necessidades vitais; 2) direitos fundamentais são aqueles que possuem validade segundo o direito positivo, isto é, aquele que está sancionado no nosso ordenamento jurídico; 3) toma como base a efetividade, ou seja, refere-se à origem histórica ou fundamento sociológico conquistado pela civilização; 4) direitos fundamentais são aqueles direitos que são atribuídos para todos enquanto cidadãos e capazes de agir como tal.

Amarthya Sen (2010) discorre sobre três preocupações muito distintas que os críticos tendem a apresentar com respeito ao edifício intelectual dos direitos humanos. A primeira ele chama de crítica à legitimidade, isto é, os direitos têm que ser adquiridos por meio de legislação:

É melhor conceber os direitos humanos como um conjunto de pretensões éticas, as quais não devem ser identificadas com direitos legais legislados. Mas essa interpretação normativa não precisa anular a utilidade da ideia de direitos humanos no tipo de contexto no qual eles são comumente invocados. As liberdades que são associadas a direitos específicos podem ser o ponto de enfoque apropriado para debate. Tem-se de julgar a plausibilidade dos direitos humanos como um sistema de raciocínio ético e como a base de reivindicações políticas (SEN, 2010, p.295).

O autor faz um comparativo sobre o surgimento dos direitos humanos:

Os seres humanos nascem na natureza sem direitos humanos tanto quanto nascem sem roupa; os direitos teriam de ser adquiridos por meio da legislação, como as roupas são adquiridas de alguém que as faz. As roupas não existem antes de serem feitas, do mesmo modo não existem antes direitos pré-legislação (SEN, 2010, p.293).

A segunda preocupação o autor chama de crítica da coerência, isto é, os direitos são pretensões que requerem deveres correlatos: "afirmar que todo ser humano tem direito a alimento ou a serviços médicos, mas, se não houver sido caracterizado nenhum dever específico de um agente, esses direitos não podem realmente 'significar' grande coisa" (SEN, 2010, p.293).

Os direitos de uma pessoa são correlatos ao dever de um outro agente de dar a primeira esse direito. Amarthya Sen relembra que Kant chama isso de obrigação perfeita: “[...] há quem não veja sentido nenhum em um direito se este não for associado ao que Immanuel Kant denominou uma 'obrigação perfeita' - um dever específico de agente específico de realizar esse direito" (SEN, 2010, p. 296). 
Por fim, Sen indaga se esses direitos são realmente universais e para todos, o que ele chama de crítica cultural: esses direitos são realmente universais? "Para justificar seu nome, os direitos humanos requerem universalidade, mas existem valores universais?" (SEN, 2010, p. 294).

Pode-se citar nesse aspecto universal o famoso caso do Tribunal Europeu dos Direitos Humanos (TEDH), Dudgeon contra o Reino Unido, o primeiro caso de sucesso perante o Tribunal sobre a criminalização da homossexualidade masculina. Em 1981, foi decidido (com base no art. 8, I, da Convenção Europeia de Direitos Humanos) a criminalização da Irlanda do Norte porque esse país considerava atos homossexuais como violação de direitos: "Qualquer pessoa tem direito ao respeito da sua vida privada e familiar, do seu domicílio e da sua correspondência". Posteriormente, esse famoso caso serviu como precedente legal para criminalizar o comportamento homofóbico tanto de vítimas do sexo masculino como feminino na Europa (L'EUROPE, 2019, Online).

No Brasil, deve-se citar como justificativa o art. $1^{\circ}$ da CF que trata dos fundamentos da República Federativa do Brasil na busca do bem-estar social e da proteção dignidade da sociedade: "A República Federativa do Brasil, formada pela união indissolúvel dos Estados e Municípios e do Distrito Federal, constitui-se em Estado Democrático de Direito e tem como fundamentos: I - a soberania; II - a cidadania; III - a dignidade da pessoa humana [...]" (BRASIL, 1988, Online).

Sendo assim, o Estado Democrático de Direito é o garantidor desses fundamentos. Faz-se necessária a proteção jurídica desse grupo social usurpado dos seus direitos, como o principal deles: a vida e a dignidade.

Nesse contexto, e em se tratando de lentos avanços no Congresso Nacional, importante tratar sobre o projeto de lei que prevê o LGBTcídio como qualificadora do crime de homicídio.

\subsection{LGBTCÍDIO}

O direito à vida, direito fundamental do ordenamento jurídico brasileiro, encontra-se previsto no artigo 5, caput, da Constituição Federal de 1988 (Online): “Todos são iguais perante a lei, sem distinção de qualquer natureza, garantindo-se aos brasileiros e aos 
estrangeiros residentes no País a inviolabilidade do direito à vida, à liberdade, à igualdade, à segurança e à propriedade".

O projeto de lei no 7.292 de 2017 (BRASIL, 2019/b, Online), de autoria da então Deputada Federal, Luizianne Lins - PT/CE, altera o art. 121 (crime de homicídio) do DecretoLei no 2.848, de 7 de dezembro de 1940 - Código Penal, para prever o LGBTcídio como circunstância qualificadora, e o art. $1^{\circ}$ da Lei no 8.072, de 25 de julho de 1990, para incluir o LGBTcídio no rol dos crimes hediondos. No caso, uma redundância, já que o homicídio qualificado, encontra-se taxado na lei de crimes hediondos, e o LGBTcídio nada mais é que uma qualificadora do crime de homicídio, equiparado a qualificadora desse crime, o feminicídio. Tendo também semelhante justificativa.

Esse projeto teve como motivações o emblemático caso Dandara (ALVES, 2019, Online), crime que ocorreu no dia 15 de fevereiro de 2017, a travesti ${ }^{4}$ que foi espancada até a morte no bairro Bom Jardim na cidade de Fortaleza no Estado do Ceará, e também pelo fato de o Brasil ser o país onde mais se assassina homossexuais no mundo, conforme site do Senado Federal:

O Brasil registrou 445 casos de assassinatos de homossexuais em 2017, segundo o levantamento do Grupo Gay da Bahia. De acordo com a ONG Transgender Europe, entre 2008 e junho de 2016, 868 travestis e transexuais perderam a vida de forma violenta (BRASIL, 2019, Online).

A qualificadora LGBTcídio pretende alterar o art. 121 do Código Penal. O LGBTcídio ocorrerá quando houver homicídio contra pessoas da comunidade LGBT por razões de sua condição, ou seja, quando o homicídio envolver menosprezo ou discriminação por razões de sexualidade e identidade de gênero (BRASIL, 2019/b, Online).

Conforme relatório da violência homofóbica no Brasil, que sistematizou denúncias pelo Disque Direitos Humanos, da Secretaria de Direitos Humanos da Presidência da República, Ouvidoria do Sistema Único de Saúde (SUS) e Ouvidoria da Secretaria de Políticas para as Mulheres (SPM): "Em 2013, foram registradas pelo Disque Direitos Humanos (Disque 100) 1.695 denúncias de 3.398 violações relacionadas à população LGBT, envolvendo 1.906 vítimas e 2.461 suspeitos" (BRASIL, 2019/c, Online).

\footnotetext{
${ }^{4}$ Utiliza-se, para a presente pesquisa, o referido termo por compreender que melhor se adapta à Dandara. Registra-se o conhecimento da diferença terminológica entre travesti e transexual, sendo esse um termo que teve origem na psiquiatria, enquanto aquele de um movimento social, sendo que ambos estão sendo ressignificados pela comunidade LGBTQIA+.
} 
Sobre os direitos humanos, precisa-se defender um valor, para isso deve-se justificá-lo. Nesse caso sobre a necessidade de proteção contra à LGBTfobia e LGBTcídio, essa razão tem como origem as pesquisas citadas acima. Assim, o fundamento irá delimitar o direito a ser tutelado pelo Estado, fazendo-se necessário ser positivado pelo legislativo. E para chegar à prática desses direitos é preciso estarem claras suas ideias (ROBLES, 1992).

A discriminação do grupo social deve-se, além de toda uma omissão cultural e educacional, ao fato de ainda existir lacuna legislativa sobre a temática junto ao apelo ideológico, ocasionando o distanciamento da classe LBGTQIA+ ao acesso aos direitos e garantias constitucionais que objetivam a proteção e o bem-estar social.

Alexandre de Moraes fala que a negativa da positivação da matéria tem como consequência a desarmonia dos julgadores que acabam prejudicando os Direitos Humanos Fundamentais (MORAES apud LEHFELD; MENDONÇA, 2015).

Buscou-se, assim, no Judiciário, a proteção desses direitos por acreditar que este Poder tem como prerrogativa a defesa das minorias sociais para que possa proteger as questões jurídicas relacionadas ao grupamento LBGTQIA+, observando o princípio da afetividade no desenvolvimento social (LEHFELD; MENDONÇA, 2015).

É certo que, aparentemente, a criminalização ou não de uma conduta diz respeito a um tema que, em regra, seria de legitimidade do poder legislador para tratar do assunto, visto que esse Poder do Estado Democrático de Direito é composto por membros eleitos diretamente para representar o povo (KELSEN, 2003), assim, é, em tese, do Poder Legislativo a capacidade institucional (ARGUELHES; LEAL, 2011, p. 6-50) para decidir e legislar sobre matérias de moral pública e de interesse geral da sociedade. No entanto, é necessário reconhecer que o Poder Judiciário pode ingressar nessa esfera quando o tema trata de direitos fundamentais e há manifesta inépcia do Legislativo, posto que

Se pesquisarmos o histórico recente das proposições legislativas que tramita(ram) no Congresso Nacional a respeito de direitos fundamentais, desde aquelas que efetivamente passaram pelas Comissões até aquelas que foram simplesmente "abortadas de início", sem maiores discussões sobre seu mérito ou que foram arquivadas por falta de manifestação e compararmos estas proposições com os respectivos temas que têm sido levados aos tribunais, temas sobre os quais não há lei (ou esta está caduca), veremos que parte da litigância se dá em razão da incapacidade do Legislativo em oferecer respostas às demandas. (NUNES; BAHIA, 2009, p. 65) grifo do autor. 
É importante notar que quando um dos poderes da República se mostra inepto em algo por muitos anos, deve-se compreender que houve decisão, qual seja, a de não decidir sobre o assunto. Decerto, quando se trata de direitos fundamentais, é da capacidade institucional do Supremo Tribunal Federal a defesa e efetivação da Constituição, sob pena de negar, à um grupo minoritário, a defesa de seus direitos. ${ }^{5}$

\section{ANÁliSANDO OS VOTOS DOS MINISTROS DO STF SOBRE O CRIME DE "LGBTFOBIA".}

A crise constitucional no Brasil é antiga, nas palavras de Paulo Bonavides (2003, p.195): “[...] tal crise se assemelha a um vulcão, ora adormecido, ora em erupção, deitando não raro sua lava fumegante sobre as instituições, e calcinando os edifícios do Império e da República em distintas épocas constitucionais e políticas do passado". O autor ainda completa, afirmando que tal crise atinge a separação de poderes: "chegou aos nossos dias como um fantasma que ronda a democracia, o sistema representativo, a separação de poderes" (BONAVIDES, 2003, p. 195).

No Império brasileiro, inexistia o controle de constitucionalidade. A Constituição era unicamente protetora dos direitos de primeira geração e do princípio da separação de poderes (BONAVIDES, 2003).

Faz-se necessário, para aprimorar o debate, abordar o princípio da separação dos poderes, que é um princípio fundamental do Direito Constitucional, para adoção do Estado Democrático de Direito.

Compreende-se como separação dos poderes a forma tripartite do Estado: Poder Legislativo, Executivo e Judiciário. No Legislativo, encontramos a figura do legislador, eleito pelo voto popular para representá-lo na Casa do Povo, responsável pela criação de normas. O Poder Executivo tem como função a governabilidade do povo e administração dos interesses públicos. Já o Judiciário cumpre a função jurisdicional, tendo a obrigação de aplicar o direito aos casos concretos e dirimir conflitos.

\footnotetext{
${ }^{5}$ É importante frisar que o pleito da comunidade LGBTQIA+ não é a propriedade de privilégios frente à sociedade, mas tão somente a existência de uma efetiva proteção do ordenamento jurídico brasileiro para crimes que ocorrem pela condição sexual ou identidade de gênero de cada um.
} 
Costuma-se atribuir a ideia de separação dos poderes à Montesquieu, todavia foi na época dos antigos gregos e romanos que tal conceito foi disseminado e trabalhado, quanto ao Direito e Filosofia. Nas palavras de Ives Gandra da Silva Martins:

O que Locke e a Inglaterra ofertaram para o aprofundamento temático de Montesquieu foi a tripartição equilibrada do poder. Hoje, estamos convencidos quanto mais lemos os autores modernos - de que, em matéria de Direito, pouco se acrescentou ao que os romanos criaram; e, em matéria de Filosofia, pouco se acrescentou ao que os gregos desvendaram. Qualquer filósofo posterior, como Políbio, que era também historiador, passando por Hume, Hobbes, Locke, Bacon, Maquiavel - historiador, filósofo, político e sociólogo - Russeau e outros, traz pequena contribuição ao pensamento universal descortinado pelos gregos. Tenho a impressão de que depois dos gregos pouca coisa se pôde criar. Criaram-se variações inteligentes, mas o tema central de Filosofia se encontra na Grécia e do Direito em Roma. Ora, com a tripartição equilibrada de poderes e Montesquieu, chega-se à discussão do sistema de governo, já a esta altura, após a Revolução Francesa, eliminando-se de vez a possibilidade de se discutir a permanência de monarquias absolutas (MARTINS apud MORAES, 2007, p.385-387).

Para Paulo Bonavides, a Constituição de 1988 foi a melhor entre as todas as Constituições Brasileiras:

Onde ela mais avança é onde o Governo mais intenta retrogradá-la. Como Constituição dos direitos fundamentais e da proteção jurídica da Sociedade, combinando assim defesa do corpo social e tutela dos direitos subjetivos, ela fez nesse prisma judicial do regime significativo avanço (BONAVIDES, 2003, p. 204).

Bonavides completa seu pensamento afirmando que a Constituição fez do STF um tribunal de guarda da Constituição, porém tal instituto sucumbiu dessa função: “[...] mas nesse ponto se autodemitiu da importantíssima e crucial tarefa de concretizar nas controvérsias do sistema, onde as bases da democracia constitucional estavam em jogo, a sua missão protetora de salvaguarda das instituições" (BONAVIDES, 2003, p. 204).

A Constituição Federal (1988, Online) prevê por meio do art. 3 que "constituem objetivos fundamentais da República Federativa do Brasil: promover o bem de todos, sem preconceitos de origem, raça, sexo, cor, idade e quaisquer outras formas de discriminação"; e no seu art. $5^{\circ}$, inciso XLI: “a lei punirá qualquer discriminação atentatória dos direitos e liberdades fundamentais".

Comemorando os 30 anos da criação da Lei de Racismo ${ }^{6}$, o STF decidiu no dia 13 de Junho de 2019 que a transfobia e homofobia (genericamente denominados de LGBTfobia)

\footnotetext{
${ }^{6}$ Lei no 7.716 , de 5 de janeiro de 1989 que define os crimes resultantes de preconceito de raça ou de cor.
} 
deve ser equiparada ao crime de racismo ${ }^{7}$. Essa é uma medida temporária, até que o Congresso Nacional crie uma legislação específica sobre esta temática (MARTINELLI, 2019, Online).

Nessa perspectiva, aborda-se a votação dos ministros do STF sobre a temática fazendo um comparativo entre o positivismo normativo prescritivo de Jeremy Waldron e o interpretativismo de Ronald Dworkin.

O resultado da votação foi 8 votos a favor e 3 contra para criminalizar a LGBTfobia, reconhecendo a mora do legislador em proteger a vida e a dignidade da comunidade. Os três ministros Ricardo Lewandowski, Marco Aurélio Mello e Dias Toffoli foram os votos divergentes à equiparação deste tipo de violência ao crime de racismo (MARTINELLI, 2019, Online).

$\mathrm{Na}$ ocasião, duas ações foram analisadas, entre elas a criminalização supracitada e a outra julgava sobre a omissão do Congresso Federal em legislar sobre a temática. O resultado da segunda ação foi 10 votos a favor e 1 contra, do Ministro Marco Aurélio Mello (MARTINELLI, 2019, Online).

A Ministra Cármem Lúcia (MARTINELLI, 2019, Online), a qual iniciou a sessão, votou a favor, tanto pela criminalização quanto pela omissão do Legislador: "Todo preconceito é violência. Toda discriminação é forma de sofrimento. Mas aprendi que alguns preconceitos causam mais sofrimento porque alguns castigam desde o seu lar, só pela circunstância de tentar ser o que é".

O Ministro Ricardo Lewandowski votou a favor reconhecendo a morosidade do Congresso, entretanto votou contra o STF legislar sobre essa temática, para ele essa é da competência do Legislativo: “A extensão do tipo penal para abarcar situações parece atentar para o princípio da reserva legal que constitui uma garantia fundamental que promove a segurança jurídica de todos” (MARTINELLI, 2019, Online). O Ministro Dias Toffoli, presidente da Corte acompanhou o voto de Lewandowski (MARTINELLI, 2019, Online).

Já o Ministro Marco Aurélio Mello considerou improcedentes as duas ações (MARTINELLI, 2019, Online). O Ministro Gilmar Mendes votou a favor nas duas ações:

\footnotetext{
${ }^{7}$ Assim, o STF entendeu que quem ofender, discriminar homossexuais ou transgêneros está sujeito a pena de 1 a 3 anos de prisão. A punição também possui o caráter inafiançável e imprescritível, assim como estipula a Lei de Racismo (MARTINELLI, 2019, Online).
} 
“Aqui está em jogo a verificação do não cumprimento de dever de proteção constitucional a questões centrais de ordem democrática" e "Orientação sexual e identidade de gênero são essenciais à pessoa humana, à autodeterminação do indivíduo de projetar própria vida e buscar felicidade" (MARTINELLI, 2019, Online). Os demais ministros acompanharam o voto de Gilmar Mendes.

O controle de constitucionalidade tem por função zelar pela Constituição Federal, e decidir sobre possíveis violações de normas constitucionais da Carta Magna. Entretanto o ativismo judicial vem crescendo e as intromissões do Poder Judiciário contribuem para o enfraquecimento do Legislativo (FARIAS; GALVÃO, 2015, p. 22):

Nos últimos anos, a procura pelo Judiciário para resolver conflitos de discordância sobre decisões legislativas por meio do controle judicial de constitucionalidade tem feito prevalecer a vontade dos juízes sobre o que fora decidido na legislatura. A crescente interferência do Poder Judiciário sobre as decisões tomadas no Poder Legislativo faz com este se torne submisso às normas jurídicas.

Pode-se dizer também que essa interferência do Judiciário ofende a separação dos poderes. Conforme Kant, o Estado ideal tem como fundamento essa separação, como observa Santos:

\begin{abstract}
A insistência de alguns filósofos políticos modernos e também de Kant na vantagem do sistema representativo e do sistema de divisão de poderes visava introduzir mecanismos de limitação, mas também de mediação e de filtragem que prevenissem as possíveis perversões funcionais do exercício da soberania e do poder, impedindo, no primeiro caso, que se legislasse em benefício direto próprio ou diretamente contra o direito de alguém em particular, ou, no segundo caso, que se governasse interpretando ou aplicando a lei comum em benefício próprio ou ao sabor de interesses particulares. Assim se garantiria a boa saúde das funções essenciais da comunidade política ou da república. (SANTOS, 2010, p. 45)
\end{abstract}

$\mathrm{Na}$ sua crítica ao controle de constitucionalidade forte, Waldron alega que falta legitimidade referindo-se aos princípios de representação e igualdade política, pois como a decisão é dada por uma pequena parcela de juízes não eleitos, retiraria da população a participação na decisão (WALDRON, 2006).

Para eliminar o controle de constitucionalidade, Waldron defende que existem algumas premissas a serem observadas. Entre elas, o Estado deve possuir um Legislativo atuante, com voto direto, diversos partidos políticos e uma sociedade democrática, como é o caso dos Estados Unidos:

This society has a broadly democratic political system with universal adult sulfrage, and it has a representative legislature, to wich elections are held on a fair and regular basis .I assume that this legislature is a large deliberative body, accustomed 
to dealing with difficult issues, including importante issues of justice and social policy . The legislators deliberate and vote on public issues, and the procedures for law making are elaborate and responsible, and incorporate various safeguards, such as bicameralism, ro bust committee scrutiny, and multiple levels of consideration, debate, and voting ${ }^{8}$. (Waldron, 2006, p.1361).

Em sentido oposto ao pensamento de Waldron, encontra-se Dworkin que defende o controle de constitucionalidade por parte do Judiciário por possuir melhores argumentos justamente na defesa das minorias sociais (DWORKIN, 2002).

O autor também defende que o juiz se encontra em melhor posição por não sofrer pressão política do eleitorado, que gostaria de ver seus interesses próprios protegidos, estando assim mais apto a analisar os argumentos (DWORKIN, 2002).

O autor defende que a legítima democracia não pode se basear somente em decisões da maioria: "a melhor estrutura institucional é aquela que produz as melhores respostas para a pergunta (de caráter essencialmente moral) de quais são efetivamente as condições democráticas e que melhor garante uma obediência estável a essas condições." (FARIAS; GALVÃO, 2012, p. 11).

Para Dworkin, o argumento que as decisões judiciais ofendem a democracia é fraco, como referência ele cita as democracias que acatam o constitucionalismo, pois esse sistema permite que legisladores tomem a decisão com base na vontade da maioria, que nem sempre são favoráveis a ela, negando dessa forma o princípio de justiça (FARIAS; GALVÃO, 2012).

Para Waldron (2002, p. 6) deve-se saber lidar com os desejos de diversas partes, já que as pessoas têm diferentes posições sobre os direitos que elas pensam dispor:

\begin{abstract}
If we live in a society where people disagree about what rights we have or about what the rights we have mean, we have to figure out some processes whereby some determinate set of answers can stabilize and provide a framework even in the face of those disagreements. We have to settle on certain political procedures to handle inputs from people who hold disparate positions about this, all of whom are convinced that they have the right answer about rights and justice? ${ }^{9}$.
\end{abstract}

\footnotetext{
${ }^{8}$ Tradução própria: Esta sociedade tem um sistema político amplamente democrático, com um sufrágio adulto universal, e tem uma legislatura representativa, para a qual as eleições são realizadas de forma regular e justa. Suponho que esta legislatura seja um grande órgão deliberativo, acostumado a lidar com questões difíceis, incluindo importantes questões de justiça e política social. Os legisladores deliberam e votam em questões públicas, e os procedimentos para a elaboração de leis são elaborados e responsáveis, e incorporam várias salvaguardas, como o bicameralismo, o escrutínio das comissões e vários níveis de consideração, debate e votação.

${ }^{9}$ Tradução própria: Se vivemos em uma sociedade em que as pessoas discordam sobre os direitos que temos ou sobre quais são os direitos que temos, precisamos descobrir alguns processos pelos quais um determinado conjunto de respostas pode se estabilizar e fornecer uma estrutura mesmo diante dessas divergências. Temos que nos conformar com certos procedimentos políticos para lidar com as contribuições de pessoas que detêm
} 
Diante do entendimento antagônico acima exposto entre os autores Waldron e Dworkin, referente ao controle de constitucionalidade, percebe-se a existência de pontos fortes e fracos entre as duas correntes, que se mostram úteis não para apreciar se o controle de constitucionalidade é válido ou não no Brasil, já que é indiscutível sua constitucionalidade, mas para traçar com mais clareza seus limites, evitando que se ultrapasse as fronteiras que separam a atividade legislativa e judiciária.

Contudo, apesar da discussão sobre a existência de ativismo judicial na realidade brasileira, especificamente na decisão do STF sobre LGBTfobia e LGBTcídio percebe-se que foi adotado dois caminhos dissociados. A maioria do Plenário entendeu que de um lado "até que o Congresso Nacional edite lei específica, as condutas homofóbicas e transfóbicas, reais ou supostas, se enquadram nos crimes previstos na Lei 7.716/2018 e, no caso de homicídio doloso, constitui circunstância que o qualifica, por configurar motivo torpe" (STF, 2019, Online).

Por fim, estabeleceu que "o conceito de racismo ultrapassa aspectos estritamente biológicos ou fenotípicos e alcança a negação da dignidade e da humanidade de grupos vulneráveis" (STF, 2019, Online).

Ocorre que na primeira justificativa da tese, o Supremo aplicou o instituto da analogia para equiparar a LGBTfobia às penalidades do crime de racismo e qualificar o LGBTcídio como motivo torpe, tudo tendo em vista a mora do Congresso Nacional. A decisão, então, serviria como uma forma temporária de resolução da problemática discriminatória desse grupamento até que fosse posteriormente legislada por matéria específica. Nesse caso, constata-se o ativismo judicial sobre matéria penal, fato que é proibido pelo princípio da reserva legal, ao menos no concernente à criminalização por analogia.

Porém, no segundo fundamento sobre o tema, o STF estendeu o conceito de raça para abranger a comunidade LGBT. Nesse caso, houve uma interpretação conforme a Constituição, atribuição normal das competências da mais alta corte constitucional do país. Sendo assim, se esse tivesse sido o único caminho adotado pela decisão, não haveria necessidade de uma futura legislação, pois a Lei de crime racial já estaria abrangendo essa comunidade sem precisar de outras formalidades.

posições diferentes sobre isso, todos os quais estão convencidos de que eles têm a resposta certa sobre direitos e justiça. 


\section{CONCLUSÃO}

Neste trabalho, abordaram-se considerações gerais a respeito de direitos fundamentais e desacordos jurídicos, debatendo a necessidade de regulamentação da criminalização cometida contra a classe LGBTQIA+ brasileira. Propondo, sob um ponto de vista descritivo do Direito, a discussão de autores sobre a legalização por parte do Supremo Tribunal Federal.

A marginalização legal propicia um avanço negativo da sociedade em oprimir tais direitos, pois salvaguarda-se na impunidade, principal fator de potencialização da violência.

Justificou-se a tomada de decisão com base na morosidade do Congresso Nacional em regularizar tal legislação, embora se viva em um Estado Democrático de Direito que prima pela separabilidade dos poderes, e a afastabilidade do ativismo judicial em matéria penal. Ainda assim, exige-se uma posição imediata do Congresso Nacional para criminalização de toda forma de discriminação desse grupamento social, pois pesquisas demonstraram essa necessidade, já que o Brasil lidera o ranking de assassinatos a homossexuais.

Dessa forma, chega-se à conclusão que Jeremy Waldron prima pela separabilidade de poderes no âmbito de legislar, já que o legislador se trata de classe representativa da vontade popular, e que, em contraposição a Ronald Dworkin defende a primazia do Judiciário, pois entende que ele não sofre pressão social e possui conhecimento sobre tal assunto de forma aprofundada para melhor solucionar os problemas concretos da sociedade.

A fim de se evitar essa intromissão do Judiciário, e principalmente a interferência legislativa em matéria penal, que enfraquece o poder legislativo e consequentemente desarmoniza o Estado Democrático de Direito, com base no princípio da reserva legal, faz-se necessária pressão junto aos membros do Congresso Nacional para que regulamente tais legislações pertinentes a matéria, como a LGBTfobia e LGBTcídio, devendo o Poder Legislativo atentar-se aos pleitos sociais.

Por fim, conclui-se que, diante da cultura e do ordenamento jurídico brasileiro, há necessidade de criminalização de atos cometidos contra a condição sexual ou identidade de gênero do indivíduo, mas critica-se o método empregado pelo STF na decisão sobre o 
assunto, já que tomou dois vieses contraditórios. Se apenas tivesse escolhido adotar o caminho da interpretação conforme a Constituição teria se distanciando do protagonismo judicial e privilegiado o princípio da unidade constitucional, garantindo o mesmo resultado ao qual se chegou, sem maiores divergências sobre separação dos poderes.

\section{REFERÊNCIAS}

ALVES. Letícia. Projeto transforma LGBTcídio em crime hediondo. Data da Publicação: 12 de Dezembro de 2017. Disponível em:

<https://www.opovo.com.br/jornal/politica/2017/12/projeto-transforma-lgbtcidio-em-crimehediondo.html>. Acesso em 23 de Junho de 2019.

ARGUELHES, Diego Weneck; LEAL, Fernando. Os argumentos das "capacidades institucionais" entre a banalidade, a redundância e o absurdo. Revista Direito, Estado e Sociedade, Rio de Janeiro, v., n. 38, p. 6-50, jan./jun. 2011.

BONAVIDES, Paulo. Teoria Constitucional da Democracia Participativa: por um direito constitucional de luta e resistência por uma nova hermenêutica por uma repolitização da legitimidade. Editora: Melheiros Editores LTDA, $2^{\text {a }}$ edição, 2003.

BORTONI. Larissa. Brasil é o país onde mais se assassina homossexuais no mundo. Data da Publicação: 16 de Maio de 2018. Disponível em:

$<$ https://www12.senado.leg.br/radio/1/noticia/brasil-e-o-pais-que-mais-mata-homossexuaisno-mundo>. Acesso em: 23 de Junho de 2019.

BRASIL. Câmara dos Deputados: PL 7292/2017. Disponível em:

<https://www.camara.leg.br/proposicoesWeb/fichadetramitacao?idProposicao=2128135>. Acesso em: 23 de Junho de 2019/b.

Constituição (1988). Constituição da república federativa do Brasil. Brasília, DF:

Senado Federal: Centro Gráfico, 1988.

Secretaria Especial de Direitos Humanos do Ministério das Mulheres, da Igualdade Racial e dos Direitos Humanos. Relatório de Violência Homofóbica no Brasil: ano 2013. Disponível em:

<http://www.direito.mppr.mp.br/arquivos/File/RelatorioViolenciaHomofobicaBR2013.pdf>. Acesso em: 23 de Junho de 2019/c.

Senado Federal: Projeto de Lei $n^{\circ}$ 672, de 2019. Disponível em:

<https://www25.senado.leg.br/web/atividade/materias/-/materia/135191>. Acesso em 23 de junho de 2019/a.

Alexandre de. Direito Constitucional. 21. ed. - São Paulo: Atlas, 2007. 
Jeremy. The Core of the Case against Judicial Review. Yale Law Journal, vol. 115, n. 6, 2006, p. 1346-1407.

DWORKIN, Ronald. Levando os Direitos à Sério: Tradução e Notas de Nelson Boeira - São Paulo: Martins Fontes, 2002.

FARIAS Maraíse Sobral de; GALVÃO Jorge Octávio Lavocat. Controle de Constitucionalidade e Democracia: um embate entre Ronald Dworkin e Jeremy Waldron. Disponível em <http://dspace.idp.edu.br:8080/xmlui/bitstream/handle/123456789/2129/Artigo_Maraisa\%20 Sobral\%20de\%20Farias.pdf?sequence=1\&isAllowed=y>. Acesso em: 23 de Junho de 2019.

FERRAJOLI, Luigi. Temas atuais do Direito. Tradução de Alexandre Salim e Hermes Zaneti. Rio de Janeiro: Lumen Juris: 2011.

GOMES, Luiz Flávio. Direito penal: parte geral: volume 2. - São Paulo: Editora Revista dos Tribunais, 2007.

KELSEN, Hans. A democracia. São Paulo: Martins Fontes, 2003.

L'EUROPE. Conseil de. Case of Dudgeon v. the United Kigdom. Data da publicação: 22 de Outubro de1981. Disponível em: <http://ceere.eu/wp-content/uploads/2016/03/CASE-OFDUDGEON-v.-THE-UNITED-KINGDOM.pdf>. Acesso em: 23 de Junho de 2019.

LEHFELD, Lucas; MENDONÇA, Marina. Direito Homoafetivo: A Tutela Constitucional Dos Direitos Humano Sob O Princípio da Afetividade. Direitos e garantias fundamentais I [Recurso eletrônico on-line] organização CONPEDI/UFMG/FUMEC/Dom Helder Câmara; coordenadores: Regina Vera Villas Boas, Ricardo Henrique Carvalho Salgado, Gustavo Ferreira Santos - Florianópolis: CONPEDI, 2015.

MARTINELLI. Andréa. STF define que LGBTfobia deve ser equiparada ao crime de racismo. Data da Publicação: 13 de Junho de 2019. Disponível em: $<$ https://www.huffpostbrasil.com/entry/criminalizacao-dalgbtfobia_br_5d02949de4b0304a120bf758>. Acesso: 23 de Junho de 2019.

MORAES, Alexandre de. Direito constitucional. 17. ed. São Paulo: Atlas, 2005.

NUNES, Dierle; BAHIA, Alexandre. Processo, Jurisdicao e Processualismo Contitucional Democratico na America Latina: Alguns Apontamentos. Revista Brasileira Estudos Politicos, v. 101, p. 61, 2010.

ROBLES, Gregorio. Los derechos fundamentales y la ética em la sociedade actual. Madrid (España): Civitas, S.A: 1992.

ROSSI, Marina. Maioria do STF decide que homofobia é crime. Data da Publicação: 24 de Maio de 2019. Disponível em:

<https://brasil.elpais.com/brasil/2019/05/23/politica/1558635166_112275.html>. Acesso em 23 de junho de 2019. 
ROXIN, Claus. A proteção de bens jurídicos como função do Direito Penal. 2 ed. Porto Alegre: livraria do advogado, 2013.

SANTOS, Leonel Ribeiro dos. Kant: da reinvenção do Republicanismo à ideia de uma "República Mundial". Cadernos de Filosofia Alemã, São Paulo, n. 16, julho a dezembro de 2010.

SEN, Amarthya. Desenvolvimento como liberdade. Tradução de Laura Teixeira Motta; revisão técnica Ricardo Doninelli Mendes. São Paulo: Companhia das Letras, 2010.

STF. STF enquadra homofobia e transfobia como crimes de racismo ao reconhecer omissão legislativa. Data da Publicação: 13 de jun. 2019. Disponível em:

<https://portal.stf.jus.br/noticias/verNoticiaDetalhe.asp?idConteudo=414010>. Acesso em: 17 de ago. 2019.

WALDRON, Jeremy. Disagreements on Justice and Rights. New York University Journal of Legislation and Public Policy vol. 6, n. 1, 2002, p. 5-10. 